\title{
Managing stakeholder knowledge for the evaluation of innovation systems in the face of climate change
}

\author{
Alexandros Nikas, Haris Doukas, Jenny Lieu, Rocío Alvarez Tinoco, \\ Vasileios Charisopoulos and Wytze van der Gaast
}

\begin{abstract}
Purpose - The aim of this paper is to frame the stakeholder-driven system mapping approach in the context of climate change, building on stakeholder knowledge of system boundaries, key elements and interactions within a system and to introduce a decision support tool for managing and visualising this knowledge into insightful system maps with policy implications.

Design/methodology/approach - This methodological framework is based on the concepts of market maps. The process of eliciting and visualising expert knowledge is facilitated by means of a reference implementation in MATLAB, which allows for designing technological innovation systems models in either a structured or a visual format.

Findings - System mapping can contribute to evaluating systems for climate change by capturing knowledge of expert groups with regard to the dynamic interrelations between climate policy strategies and other system components, which may promote or hinder the desired transition to low carbon societies.

Research limitations/implications - This study explores how system mapping addresses gaps in analytical tools and complements the systems of innovation framework. Knowledge elicitation, however, must be facilitated and build upon a structured framework such as technological innovation systems.

Practical implications - This approach can provide policymakers with significant insight into the strengths and weaknesses of current policy frameworks based on tacit knowledge embedded in stakeholders.

Social implications - The developed methodological framework aims to include societal groups in the climate policy-making process by acknowledging stakeholders' role in developing transition pathways. The system map codifies stakeholder input in a structured and transparent manner.

Originality/value - This is the first study that clearly defines the system mapping approach in the frame of climate policy and introduces the first dedicated software option for researchers and decision makers to use for implementing this methodology.
\end{abstract}

Keywords Decision support systems, Knowledge management, Climate policy, Technological innovation, Low carbon transitions, System maps

Paper type Research paper

\section{Introduction}

Transforming societies into low-carbon and climate-resilient systems is a complex and multi-dimensional problem domain, as it has impacts on people and institutions within the systems. Replacing conventional technologies and behaviour with climate-friendly solutions may bring about socio-economic and environmental benefits to societies but could also have negative implications such as employment losses, investment requirements or required imports of resources, which could create resistance to changes. Moreover, regions, countries or sectors may feature several inertias. For example, recent investments in coal plants can partly lock a system in fossil-fuel-dependent energy production for as long as the following two
(Information about the authors can be found at the end of this article.)

(C) Alexandros Nikas, Haris Doukas, Jenny Lieu, Rocío Alvarez Tinoco, Vasileios Charisopoulos and Wytze van der Gaast. Published by Emerald Publishing Limited. This article is published under the Creative Commons Attribution (CC BY

4.0) licence. Anyone may reproduce, distribute, translate and create derivative works of this article (for both commercial and non-commercial purposes), subject to full attribution to the original publication and authors The full terms of this licence may be seen at http:// creativecommons.org/licences/ by/4.0/legalcode

The most important part of this research is based on the H2020 European Commission Project "Transitions pathways and risk analysis for climate change mitigation and adaptation strategies TRANSrisk" under grant agreement No. 642260. The sole responsibility for the content of this paper lies with the authors. It does not necessarily reflect the opinion of the European Commission.

Received 5 January 2017 Revised 16 March 2017 Accepted 13 April 2017 
decades. Therefore, capturing the dynamic interactions between system actors and institutional processes or policies and finding ways to enhance acceptance of low-emission solutions constitute a crucial aspect of desired transformations. As a result, an array of respective evaluation methods and tools are required.

Such methods and tools already exist. For example, the systems of innovation (SI) framework can be used to describe how multiple arrangements of interlinked actors, institutions, policies and services lead to different expected or unexpected outcomes. A specific approach for describing in detail what a system looks like in terms of enabling (or disabling) environment, system actors and supporting services is that of system mapping, as originally proposed by Albu and Griffith (2005). As a stakeholder-driven visualisation technique, system maps resemble concept mapping (Trochim, 1989), while allowing for more freedom outside this strict node-link structure (Kim et al., 2003), and cognitive mapping (Axelrod, 1976) without necessarily sticking to the causal relationships between concepts (Kwong and Lee, 2009); contrary to both techniques, system mapping builds upon specific system components but offers freedom with regard to the type of concepts and nature of relationships these concepts develop with one another. System maps help define conceptual boundaries of the system under research, capture both past and present interrelationships and lock-ins as well as help to develop future pathways by understanding how services, infrastructure or - more importantly - new mitigation or adaptation policy mixes can help or hinder climate change mitigation or adaptation action.

In the perspective of sustainable development, a participatory approach helps to address the behaviour of the social groups involved in a system (Lagabrielle et al., 2010), as well as their potential reactions to changes brought about by climate change and mitigation or adaptation options (such as policy instruments, strategies, incentives, etc.). After decades of carrying out climate policy evaluation strictly among scientists and modellers, stakeholder involvement and participatory modelling in this problem domain have become very popular (Voinov and Bousquet, 2010). In this respect, a strength of system mapping is that it particularly enables participatory analyses to mobilise stakeholders' tacit knowledge of how they see, experience and perceive "their" systems and then transparently codifies that (stakeholder) knowledge into visual representation of the systems. A weak point, however, is that maps easily become complex and once drawn are difficult to change when using generic-purpose visualisation software. With such conventional techniques, it is usually difficult to document information and knowledge gained through stakeholder engagement. Moreover, when the goal of a research or policy study is to assess multiple pathways towards a low-emission future (e.g. at the level of a sector), it is desirable to draw system maps for each pathway and be able to compare these. Automation of system mapping is a way forward to improve the quality of participatory system analysis and compare different pathway options. To the best of our knowledge, however, there exist no dedicated software options for researchers and decision makers to use for implementing the market mapping methodology.

The aim of this paper, therefore, is to not only formally define the system mapping framework for exploring the dynamics in innovation systems in respect to climate change and mitigation and adaptation policy but also introduce Mapping Tool for Innovation Systems Evaluation (MATISE[1]), a dedicated tool specifically designed for the purpose of system mapping in a structured, coherent and transparent way. Specifically, MATISE is an innovative tool developed under TRANSrisk, an EU-funded project (Transrisk, 2016), that uses the strengths of system mapping as an analytical decision support approach and addresses the weaknesses of manual mapping techniques and applications. The tool enables the researcher to codify stakeholder input into a strictly structured format, which is then transformed into a visual map with clearly distinguished system components, while also featuring a number of layout optimisation algorithms for an enhanced visual outcome. It also allows for the reverse process to take place by importing system maps and 
transforming them into structured tables, thus enabling the analyst to create, modify and work on either format depending on their preferences and the underlying conditions and thus easily oversee and dynamically update large, complex maps. The presented framing also allows system maps to be produced in a structured manner while accounting for variations within different systems; thus, the maps can be a support tool in cross-sectoral and country learning and analysis.

The following section introduces the theoretical background of system mapping to explore how it addresses gaps in analytical tools and complements the SI framework; furthermore, a brief literature review of system mapping applications is conducted to explore how system maps - as an analytical decision support tool - have contributed to studying a wide range of problems, namely in the context of sustainable livelihood, deploying low-emission energy technologies and identifying environmental policy mixes. Section 3 presents the methodological framework of using system maps and MATISE for evaluating innovation systems for climate change by means of defining conceptual boundaries and capturing dynamic interactions for further analysis. In Section 4, the developed software application is presented in detail, with regard to its specifications, workflow and contribution to the proposed framework by means of examples based on a study of the UK nuclear power system. Finally, Section 5 draws conclusions and offers prospects with regard to extensibility and further potential uses of MATISE, as part of an integrated framework or basis for semi-quantitative techniques.

\section{Theoretical background}

\subsection{Systems of innovation framework}

The idea of complex systems in scientific and social science studies led researchers to focus on not just the components of any particular system but their interactions as well. Therefore, the dynamics of a system, although complex, could be explained by the summation of the parts within the units of analysis, i.e. the system (e.g. atoms, cells, individuals, social systems, production systems, etc.) plus their multiple interactions and interdependencies (Boulding, 1956; Von Bertalanffy, 1950; Wells, 2012). System theory has been applied in many scientific fields to build bridges for interdisciplinary dialogue between independent areas of study as well as within the area of systems science. This is the case for the SI framework, which is used to search and describe how multiple arrangements of interrelated economic actors and their institutions resulted in economic performances (Freeman, 1995).

The SI approach has been a large step forward to the understanding of nations' economic growth and technological change (Freeman, 1987; Lundvall, 1992; Nelson, 1993). In other words, the SI approach might be useful to research how individuals in society act individually and collectively in different forms of aggregations. For instance, SI approaches can help to understand how social systems (e.g. organisations, communities, etc.) distributed across locations (e.g. cities, nations, regions, etc.) can interact with natural and man-created artefacts or technologies and potentially lead to changes in the overall human system. The complexity of these systems might be partially explained by the interrelated embedded subsystems. For instance, a nation is composed by different subgroups of individuals, which constitute and/or work in multiple organisations (firms, universities, government agencies, NGOs, etc.) located in different areas.

The SI framework could take two main perspectives (Soumonni, 2013):

1. a narrow perspective, which focuses on mapping indicators of national specialisation and performance regarding innovation and R\&D efforts; and

2. a broader perspective, which addresses other factors and processes such as economics, education, institutional set ups, social institutions, infrastructure, etc., particularly with respect to their impact on the process of learning and competence building (Lundvall et al., 2009). 
However, the relationship cause-effect of inputs and outputs, which leads to system performance, is still poorly understood. Moreover, it will continue to be so because there are currently no principles and laws in the general system theory (Von Bertalanffy, 1950) that explain the complexity of embedded (sub-) systems. One of the main reasons is the lack of tools to identify and measure the complexity of the multiple interactions of actors/ agents/stakeholders that intervene and influence the dynamics of the system performance. The same is true for phenomena where the general principles can be described in ordinary language though they cannot be formulated in mathematical terms (Von Bertalanffy, 1950). Nevertheless, there are some principles in complex dynamic systems, which could be observed and searched particularly focused on social and environmental sustainability, such as feedback loops and networks (Wells, 2012). The interplay of elementary units could be investigated independently of each other; it might also be useful to investigate interdependencies and interconnectivity of these units and the vaguely termed "wholeness" (Von Bertalanffy, 1950).

The proliferation of different SI frameworks trying to set up the boundaries of an innovation system is still a problematic issue of the approach and in general for complex systems to define the unit of analysis, for instance, to study economic growth of continental, national and subnational innovation systems (Freeman, 2002); to define regional innovation systems (Asheim and Gertler, 2005; Asheim and Isaksen, 1997; Cooke, 1992, 2001, 2002, 2004); to compare small countries development (Padilla-Pérez and Gaudin, 2014; Padilla-Pérez et al., 2011); to define and analyse the sectoral SI and production (Breschi and Malerba, 1997; Malerba, 2002; Malerba, 2005); to identify and analyse technological innovation systems (TIS) (Carlsson and Jacobson, 1997b, 1997a; Carlsson and Stankiewicz, 1991); and sociotechnical systems (Geels, 2004; Hobday, 1998; Hobday et al., 2000); to identify learning systems (Niosi, 2002; Niosi, 2011); and to identify and analyse the sources of regional capabilities (Alvarez Tinoco, 2011).

Specifically, for innovation policy development, the TIS framework has proved to be instrumental for informing a wide range of problems including global environmental sustainability (Bergek et al., 2015, p. 51). A TIS has a structure defined by a set of components and elements, including actors, technologies, networks and institutions, which contribute to the development of a technological field (Bergek et al., 2008). Actors include organisations such as firms along the whole value chain (including those up and downstream), universities and research institutes, public bodies, influential interest organisations (e.g. industry associations and non-commercial organisations), venture capitalists, organisations deciding on standards, etc. Networks focus on learning and knowledge exchange, technology transfer and resource transfer and seek to influence the political agenda (e.g. advocacy coalitions). Institutions are the culture, norms, law and regulations prevailing in a system for a period of time (Bergek et al., 2008).

One of the assumptions of TIS and in general of SI is that its main function is to support collective capability building by actors to generate, diffuse and utilise knowledge and technologies (e.g. physical artefacts as well as technical and organisational know-how). Capabilities, then, represent the competence of the system to generate economic value (Carlsson et al., 2002, p. 235) and eventually economic growth (Edquist, 2005). Therefore, $\mathrm{SI}$ analysis might help to identify systems structures, components and interactions, which lead to changes.

The SI concepts have limitations because there has not been at present an identification of the determinants of innovation (Chaminade and Edquist, 2006), and SI is a static framework, which does not pay enough attention to the micro level (Hekkert et al., 2007) interactions among actors. To attempt to solve these problems and to understand from the structure of the system (e.g. actors, networks, institutions, etc.) and bottom up interactions, the system mapping method described in Section 2.2 might help in defining the boundary of innovative systems for climate change and to codify key dynamic interactions in the 
system, which could be used as a starting point for further analysis in evaluating or developing potential pathways for change.

\subsection{System mapping}

In this section, we introduce the first formal documented application of system maps (this does not include cognitive, causal or network mapping) and provide an overview of several key major studies that have since applied the tool. We limit our discussion of system maps in this literature review to documented studies and do not include strictly practitioner applications that are not systematically recorded due to the potential wide application across a variety of fields and regions. As a result, there are only a limited number of research studies as well as European and international projects that have formally applied this tool, which we discuss below.

System map, originally defined as a "market map", was developed by Albu and Griffith (2005) in 2002 at a workshop with Practical Action staff from Africa, Latin America and South Asia, after which it was applied in a range of projects and programmes with a focus on improving sustainable livelihoods of the rural poor. The map, as a stakeholder engagement tool, assisted with better understanding the complexity of relationships between agricultural activities, changes in the rural economy and poverty in developing countries. To improve such market chains, Albu and Griffith (2005) proposed an approach to encourage "market literacy" of stakeholders in rural areas in developing countries.

The aim was to provide stakeholders with an overarching understanding of the market chain for their business and to identify the actors with whom they can collaborate or compete with. The market map was intended as a conceptual framework for policymakers and development planners for establishing a commercial and institutional environment to support the activities of small-scale producers. A second purpose was to enable a participatory process among practitioners to communicate characteristics of the market chain as well as of the institutional environments and the service needs. With these two purposes in mind, the market map concept was developed with three core elements: the value chain (the chain of economic stakeholders owning a project as it moves from primary producers to final consumers), service providers (business or extension services that support market operations) and the enabling business environment (such as infrastructure and policies, institutions and processes that shape the market environment) (Practical Action Consulting, 2009).

Albu and Griffith's market map was aimed at improving market chain knowledge of the rural poor with a specific focus on agriculture and has been applied in studies within this sector. In this respect, Bürli et al. (2008) performed a value chain analysis using market mapping to promote mountain agricultural production systems in the aim of alleviating poverty while also preserving natural resources. Another such application can be found in Giuliani et al. (2009), where the market mapping approach is in the core of the market chain analysis of emmer production on mountain community livelihoods in Turkey in the aim of reviewing potential market opportunities for enhancing competitiveness. Byrne et al. (2013) compared the Emergency Market Mapping and Analysis toolkit (Albu, 2010), which is a simplified version of the original market mapping approach, with the Seed System Security Assessment framework (Sperling, 2008), when exploring the role of evidence in humanitarian assessment. Finally, Albu and Griffith's market map drove the value chain analysis of horticulture in Mozambique (Fink, 2014).

System maps have also been applied in a number of research projects across a wider range of sectors and countries. For instance, the EU-funded project ENTTRANS (2006-2007) explored market systems for low emission energy technologies in five countries: Chile, China, Israel, Kenya and Thailand (van der Gaast et al., 2009). In the first stage of the project, stakeholders had prioritised technology options for achieving 
long-term domestic energy goals with the lowest emissions possible within their respective countries. Once prioritised, these options were assessed in terms of what would be needed in the country for the appropriate technological application at the desired scale for meeting local development and climate goals. Applying the Market Map tool-enabled stakeholders in the ENTTRANS case studies to map out the energy sector value chains, relevant energy and climate policies and the extent to which the countries' legal, banking and educational systems could support successful implementation of priority technology options at the desired scale. Again, the tool supported knowledge gathering for policymakers and planners for better informed interventions, whereas it served as a participatory knowledge exchange tool for sector stakeholders to better understand their relevant operational system and their perceptions (Flamos and Begg, 2010; Karakosta et al., 2010).

A major application of Market Map as an analytical, participatory tool has been under the first Global Technology Needs Assessment (TNA) Project funded by the Global Environment Facility and operationalised by UNEP DTU Partnership during 2009-2013 (UNFCCC, 2013). TNAs are participatory processes aimed at supporting low- and medium-income countries in prioritising technologies for climate change mitigation and/or adaptation within their country contexts. Prioritised technologies are then assessed by countries and/or sector stakeholders with a focus on identifying barriers to their implementation in the country and finding solutions to clear these barriers. For this barrier analysis, Market Maps were suggested in the Handbook for TNAs (Dougherty and Fencl, 2009) with a direct reference to Albu and Griffith (2005) and with the same three-tiered approach focussing on enabling environment, market value chain and supporting services. Of the 31 low- and medium-income countries that conducted a TNA under the Global TNA Project, over 20 reported that they had used market mapping as a tool for characterising the relevant market system for prioritised technologies and identifying barriers within the system (TEC, 2014).

Another example of applying market mapping can be found in the EU-funded project APRAISE (2014), which aimed at explaining differences between anticipated and observed environmental policy strategies in several EU Member States. Possible differences were then explained by focussing on three explanatory factors:

1. changes in the policy contexts (e.g. impact of a recession, a green government coalition, technology breakthrough, etc.);

2. changes in the process of policy implementation policies; and

3. impacts of policies interacting with other policies.

APRAISE-applied market mapping to characterise the relevant systems for these policies and to explore where and how contextual aspects, market chain inefficiencies and unanticipated stakeholder responses to environmental policies may occur (Apraise, 2014).

Finally, the BIOTEAM project is another example of an EU project (Bioteam, 2016) that applies market maps for optimizing pathways for enhanced competitiveness of sustainable bioenergy in several EU Member States. Market mapping was used to better understand and describe the dynamics of the market systems in which the bioenergy pathways operate. The project assessed the impact of market and policy factors on selected pathways along with stakeholder interactions and also identified shocks and obstacles market systems were confronted with. Recommendations based on such type of analyses aimed to help policymakers to enhance the planning and effectiveness of individual policy instruments or policy packages and to improve mitigation of stakeholder interactions.

For this paper, we refer to market maps as "system maps", as the term "market" may have an unintended emphasis on the market supply chain or economy. We take a broader 
perspective with the mapping approach to address the complexities within innovation systems. The next section discusses how system maps can be applied as an analytical tool to explore innovation systems for climate change.

\section{The system maps framework as a research tool for climate change}

One of the challenges of analysing techno-socio-economic aspects of climate change is the scale and complexities of known and unknown problems that cut across national boundaries and intersect across sectors. System maps can assist in defining the boundaries of a study or a unit of analysis, identifying a system's main elements and its dynamics. It is not a one-size-fits-all tool rather a systematic but flexible tool that considers the unique structural context and different scales of each innovation system for climate change at the household/community, sectoral, sub-national, national, regional and/or global level.

We identify several applications for system maps in climate change research and action that includes:

- defining conceptual boundaries of the system under research; and

- capturing past and present dynamic interactions and interrelationships, which help to analyse current systems and set the framing to potentially develop future pathways.

The boundaries of complex systems may be challenging to define, particularly for TIS for climate change that involve multiple sectors, such as biomass systems that cut across energy, food and water systems. We thus propose several main elements as a framing to define the boundaries of complex systems borrowing some elements from Albu and Griffith's market map.

\subsection{Technological innovation system life cycle}

This is a life-cycle analysis or a cradle to grave approach that considers the full supply chain of a technological system for climate change. The technological system can be defined by sector and can include both stakeholders (e.g. firms) and processes. For instance, the TIS life cycle for the nuclear power electricity generation sector would include resource extraction, transportation, manufacturer reactors and other components, developers, electricity generator, waste handling facilities, storage, distribution and end-users and decommissioning. The TIS life cycle is crucial for drawing the boundaries of the system, as other elements in the system are identified based on their relation to the TIS life cycle (explained below).

\subsection{Enabling/limiting environment}

This component includes enablers and barriers that impact the development of the TIS system and can include the following:

- Policy mix: This includes the main key (sub-) national or regional policies that directly or indirectly impact the development of the TIS system. Policies may influence one part or the whole TIS lifecycle. Identifying the policy mix is a critical process that can help policymakers and other stakeholders understand how policies interact with each other, potentially resulting in synergies or inadvertently creating conflicts; this is a highly overlooked aspect, which must be further highlighted during the policy making process. Examples in the literature include productive synergies or conflicting effects when blending different energy policy instruments (Oikonomou et al., 2014) and emissions trading instruments (Boots et al., 2001) or even when integrating energy with climate policy (Oikonomou et al., 2010). For the nuclear power sector in the UK, in particular, key policies would include the Electricity Market Reform, the Nuclear Industrial Strategy, the Generic Design Assessment process and UK planning legislation. 
- Context: Contextual factors may exist at the national, regional or international level. To prevent the system map from being overly complicated, we suggest that only the key factors (e.g. economic, social, political, environmental or technological factors) that have a strong influence on either a part of or the whole TIS system be identified. For instance, key contextual factors for the UK nuclear power sector would be political support and (relative) societal buy-in.

- Institutions: The key institutions (e.g. policy-making institutions) and their respective organisations (e.g. Department of Energy) that strongly impact a part of or the whole TIS system should be identified. Stakeholders can also be individually identified if that level of detail is required for analysis, but this will increase the size of the map and complexity and should only be done so if the stakeholders are willing to be identified within the system. Formal institutions may include industry, policy, political, financial, educational, media and legal institutions. Informal "institutions" may include indigenous practices, culture, traditions, norms, etc. For instance, in the nuclear power sector, dedicated formal training institutions are identified, as they feed in highly skilled workers for the nuclear civilian and military programme.

- Infrastructure: This includes physical infrastructure that supports the TIS life cycle that is required to support the TIS system. For instance, in the nuclear power sector, the grid is an important infrastructure for delivering electricity to end-users.

\subsection{Facilitating services}

This component includes service support systems that are external to the TIS life cycle but are fundamental to facilitating the TIS system. These organisations may include banks, consultancy firms, etc.

In the process of defining the system boundaries and identifying the interactions, the institutional lock-ins are implicitly uncovered. Path-dependent processes are also identified when visual maps are used to capture the current dynamics within a system which is often dependent on past decisions.

Identifying the "dynamics" of the system depends on the research question or the direction of search. Examples of dynamics can include risks, enablers, barriers, learning processes, etc. and may differ according to specific research questions. We recommend that a clearly defined research question is drafted to guide the development of the system map, as a research question can fundamentally change the story a system map may be presenting. For instance, in a TIS system for nuclear power, a research question that asks "which elements or interactions in the nuclear power system are enablers or barriers to supporting the development of the nuclear power electricity generation in the UK?" will result in a system map that explores the positive interactions that support the nuclear power sector or the negative interactions that create barriers to developing the sector. This question would result in a map that is fundamentally different from another map that addresses the question:

Q1. Which interactions within the nuclear power sector pose risks to developing a sustainable, low carbon electricity sector in the UK?

This question could be open to interpretation on whether or not the nuclear power sector is contributing to sustainability. The positive interactions could then be those that reduce risks, as nuclear waste poses long-term risks to sustainable development. Thus, positive interactions in such a system would be those that inhibit the development of nuclear power, whereas the negative interactions could be those linked to policy incentives that encourage nuclear power development, as they could be perceived as risks to sustainable development. 
Finally, system maps may also contribute to analysing current pathways to help inform the development of further pathways (e.g. low carbon pathways) by identifying, through stakeholder engagement, the dynamics within the system that are required for a potential pathway, including processes or support needed for technological innovation, their functions and interactions within the market context and the role of policies. Such a system map would be future-looking and could be used as a complementary tool for quantitative models. A future looking map could then propose the interactions, institutions or learning processes that would be necessary to reach a low carbon pathway proposed by a model scenario or a qualitative storyline.

Overall, system maps can be developed with a high level of detail and complexity based on stakeholder engagement and/or secondary research. On the other hand, a map may be relatively concise, presenting several but essential interactions to communicate a specific message. Depending on the audience and the research purpose, it can be used to engage with stakeholders to better understand the dynamics of a system, as an analytical tool for codifying stakeholder inputs and research results or as a visual aid to present (part of) a complex system in a more digestible form to decision makers. The tool does not attempt to replace qualitative research outputs (e.g. reports, research articles, etc.) but intends to complement research methods and can be used as a support tool for desk research and/or for stakeholder engagement (discussed in greater detail below).

The next section provides detailed information on creating system maps using MATISE, which has been specifically designed for analysing innovation systems for climate change.

\section{Mapping Tool for Innovation Systems Evaluation}

\subsection{Introduction to Mapping Tool for Innovation Systems Evaluation}

Because the market mapping methodological framework was introduced by Albu and Griffith (2006), it has been applied several times in different decision contexts (as described in Section 2.2). However, there has not been a framework or dedicated tool developed for the purpose of supporting the mapping process and visualisation of the resulting maps. There currently exist a number of visualisation tools that can be used in this respect, such as the fuzzy-logic cognitive mapping modelling tool Mental Modeler (Gray et al., 2013) or diagramming and vector graphics applications such as Microsoft Visio. However, these applications were not designed specifically for the purposes of system mapping and would require significant customisation to fully develop a system map including its detailed features.

Moreover, system mapping is based on the assumption that participatory processes can mobilize a broad range of (professional or otherwise) knowledge available among stakeholders in the market, sector or country under examination. With multiple stakeholders engaged, the mapping process needs to capture different or even conflicting views, experiences, facts, etc. As a result, system mapping requires a very intensive, time-consuming process that is usually broken down into numerous steps and requires a manual modification for each change in the system map such as adding/deleting/rearranging elements (actor, policies and contextual factors) and their respective interactions within the system map. When creating a map, this whole procedure is usually manually drawn on paper or using a drawing software, which limits the map to a visual interface or a flip-over poster. This means that as the complexity of the system map - or any visual representation of a large system - increases, incorporating changes or visually supervising the model becomes challenging: when as few as a couple of system elements are added, deleted or even relocated (i.e. reassigned from one component to another), then restructuring of the map must take place for everything to fit in the canvas and still be comprehensible; using conventional tools, this would require "flipping over the paper" and redrawing the map.

VOL. 21 NO. 52017 | JOURNAL OF KNOWLEDGE MANAGEMENT | PAGE 1021 
To this end, an innovative tool has been designed specifically for the purposes of system mapping. MATISE introduces a new, structured format of system representation by first using an excel matrix interface that can be easily converted to a system map, enabling the analyst to create, modify, work on either format (excel or visual interface) depending on their preferences and thus easily supervise large, complex system maps.

\subsection{Conceptual framework}

MATISE is a reference implementation in MATLAB that aims to facilitate rapid model creation, editing and visualisation. It handles structured input in the form of Excel (XLS or XLSX) worksheets or Graph Modelling Language (GML) files. A graphical user interface (GUI) is provided, enabling the user to create or edit system models on the fly. MATLAB was chosen as the implementation platform because of its rapid prototyping features, extensive documentation and wide availability throughout research communities worldwide.

Both .xIs (or .xIsx) and .gml files can be imported as inputs in MATISE and both formats can be exported as output, allowing the tool to act as a bridge between representations (Figure 1); however, MATISE was originally developed in the aim of facilitating the creation of a map by means of a structured spreadsheet, enabling the analyst to identify key system components (including groupings defined in Section 3, such as TIS life cycle, context, enabling/limiting environment and facilitating services), concepts (individual elements in the groups such as stakeholder organisations, specific policies etc.) and relationships as well as to determine the degree/significance of the relationships and to provide a short rationale for these relationships.

The proposed methodological framework for the tool includes creating the .xIs/.xIsx model in Microsoft Excel, importing and editing the model in MATISE and exporting the visual outcome of the system map in a .gml model (Figure 2).

\subsection{Workflow}

The tool can handle a selection of different input formats that can represent system models. Currently, the supported formats are:

- Matlab files (.mat);

- Microsoft Excel worksheets (.xIs/.xIsx); and

- Graph Modelling Language files (.gml).

These formats are additionally available for exporting. Functions for reading and writing .mat and .xlsx files were already available in MATLAB. For .gml files, a custom parser that closely follows the GML specification[2] was written based on regular expressions.

Internally, MATISE creates a dictionary containing all the concept-to-group and concept-to-stakeholder mappings for the model that is being processed. Relationships between concepts are stored in an array that resembles a (weighted) adjacency matrix, using numerical values to represent different kinds of relationships. Positive/negative values indicate positively/negatively related concept pairs, whereas the absolute value

Figure 1 MATISE acts as a bridge between the structured format and the visual representation

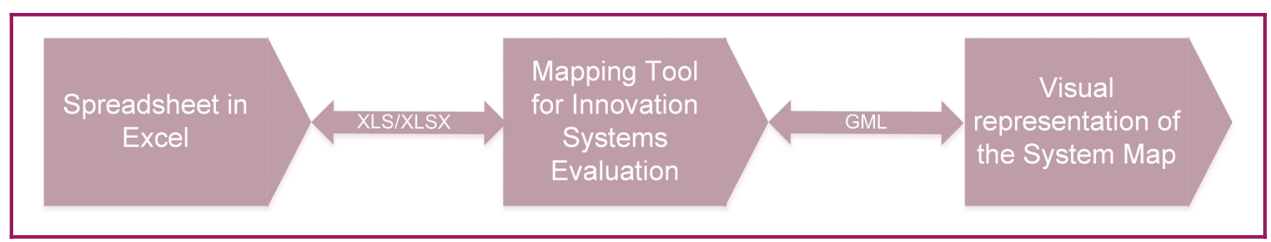

PAGE 1022 |JOURNAL OF KNOWLEDGE MANAGEMENT | VOL. 21 NO. 52017 


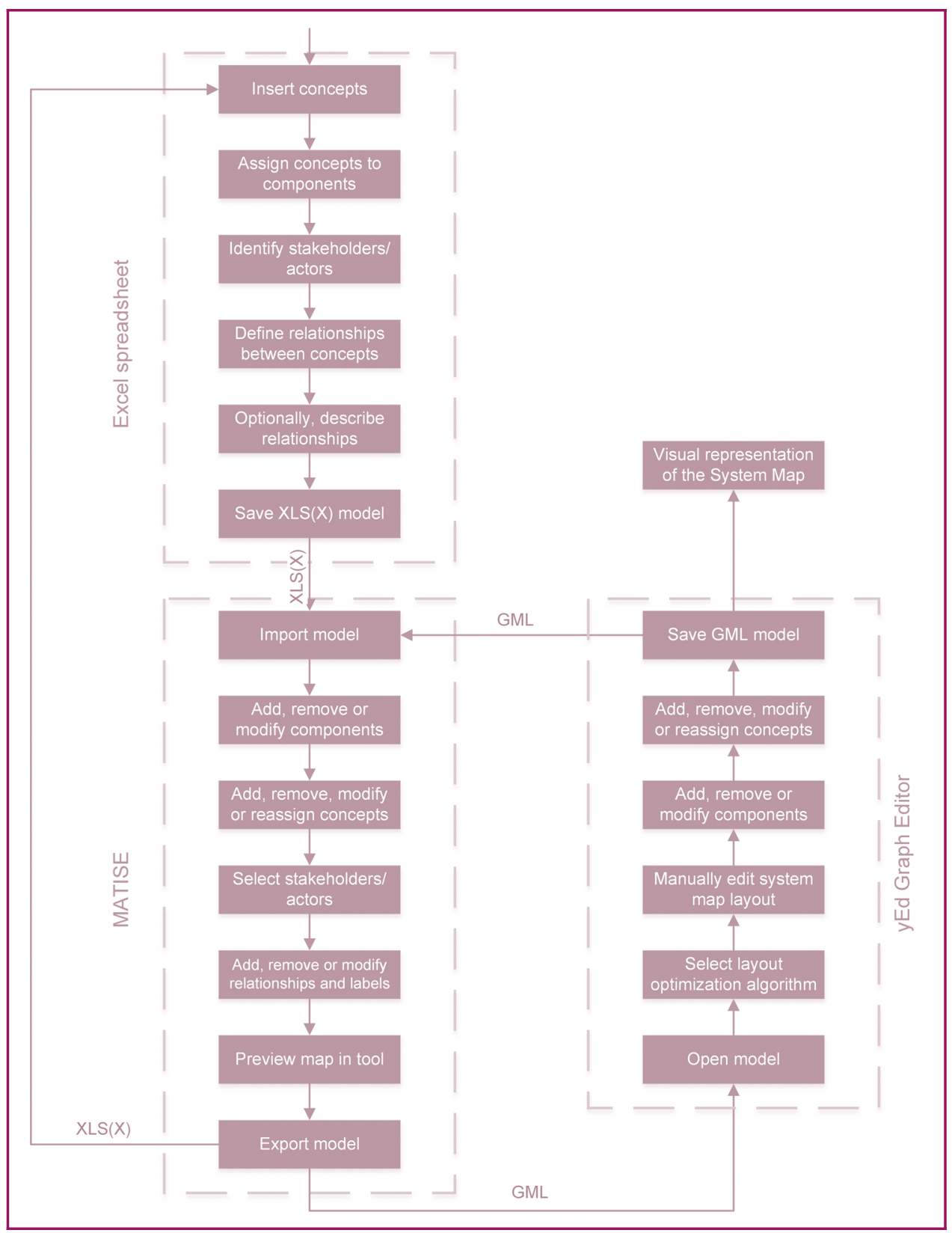

represents the degree to which the two concepts are related (Figure 3). An additional array is also created to store labels or annotations concerning a related concept pair.

The user can utilize the GUI to quickly edit the adjacency or label matrix, add, rename or delete concepts and groupings, identify stakeholders, etc. A preview of the resulting system map is also available, which is generated using graph plotting functions that come out-of-the-box with a standard MATLAB installation (Figure 2).

Concepts are visualised as graph nodes, whereas groupings become group nodes that contain sets of concepts. Concepts that have been identified as stakeholders have the shape of an ellipse to be easily identified, and non-actors are depicted as standard rectangular shapes. The relationships between concepts are visualised as graph edges, 
Figure 3 An example of how user input, namely (a) the adjacency matrix and (b) the label matrix is visualised into (c) the output system map

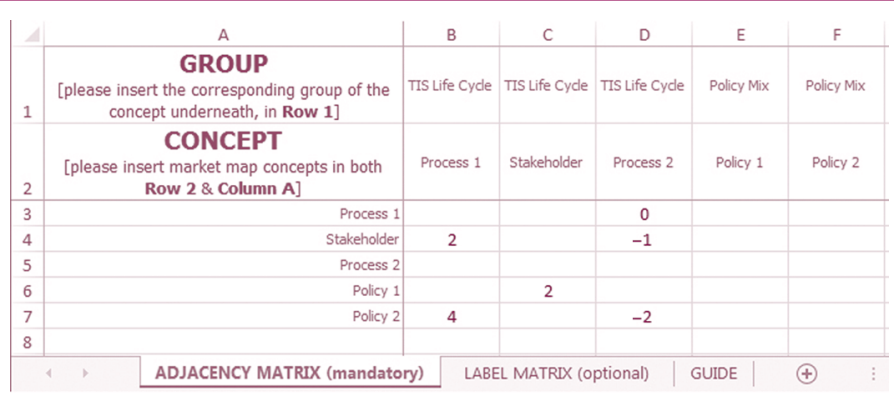

(a) adjacency matrix

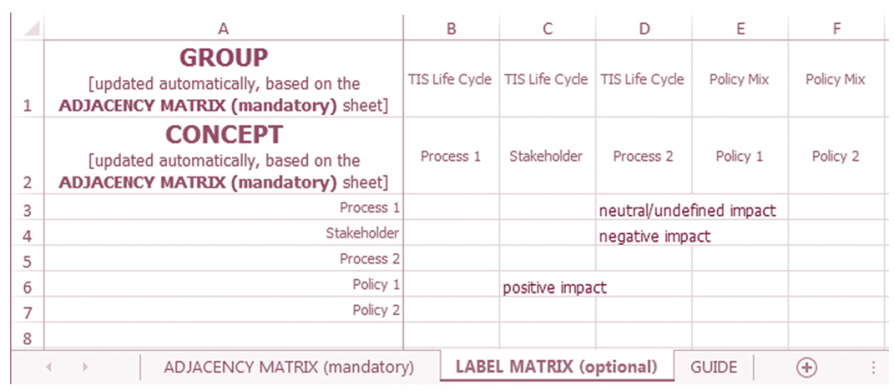

(b) label matrix

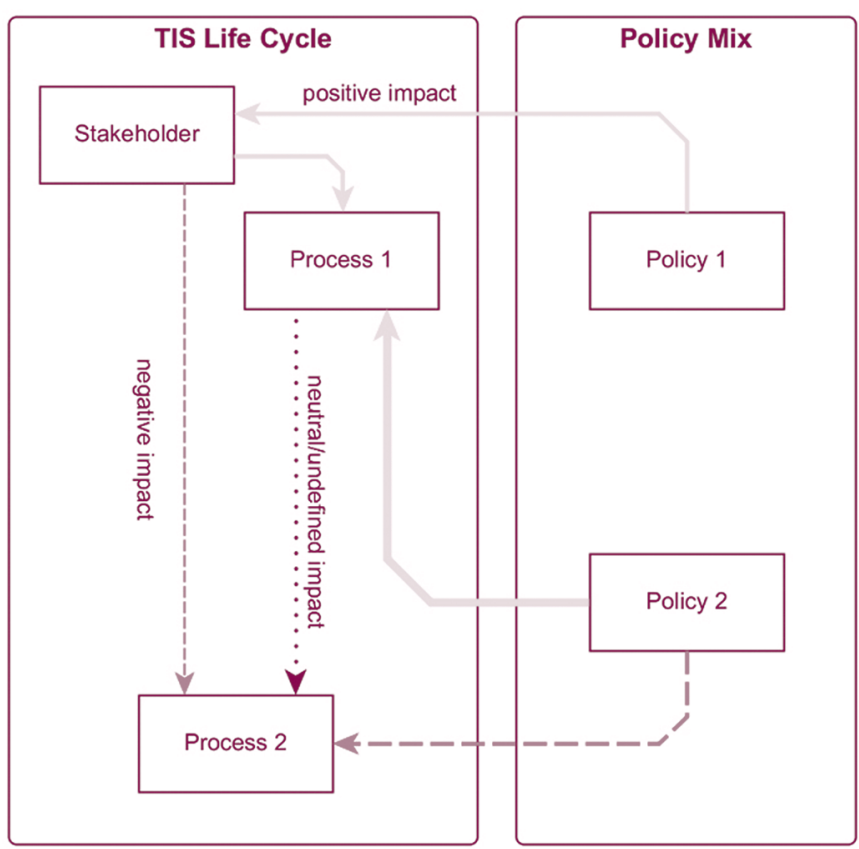

(c) system map

using different layouts (colours, solid or dotted lines, etc.) to indicate different kinds of interaction. This is further described in Section 4.5.

Visualisation is made possible via the GML, which is used internally by $y E d$, a popular graph editor that is freely available. The yEd editor can handle the GML extension effectively while offering layout optimisation algorithms (i.e. automatically formatting layout 
of components, nodes and links) that prove very useful in the case of complex maps, as usually is the case with system maps. It also provides for easily exporting the map into various extensions, such as known image extensions and HTML imagemaps, which can be further used for inserting large bits of contextual information into the map.

\subsection{Code extensibility and license}

The codebase can easily be extended with additional parsers to enable support for other formats, such as GraphML, which is an XML-like mark-up language. The GraphML format not only incorporates the same bits of network structure information that GML does but also saves exact position information of each FCM element as well; although the user can easily transform a GML file into a GraphML one - and vice versa - via yEd, directly incorporating a GraphML parser in MATISE would save them significant time. The core functionality of the tool has been implemented in modules separated from the part that handles the GUI. This way, various extensions can easily be integrated into the codebase. The MATISE is free and open source software, available under a permissive BSD license from http://transriskproject.eu/matise.zip

\subsection{Documentation}

To facilitate the user into providing their input into MATISE, we have developed a user-friendly template in Excel with three tabs (part of which can be viewed in Table I). The first tab contains the relationship matrix, which is square, meaning that all concepts of the system map included in the top row, i.e. Row 2, are duplicated in the top column. For instance, concepts in Column A are in the exact same order as Row 2, so as to be able to fully express the relationships that emerge between the various concepts of the system map. In this square matrix, therefore, any indication as to the existence of a relationship in a cell means that the row concept correspondingly impacts the column concept. It should also be noted that bold formatting in the first column indicates that said concept is a stakeholder, meaning an actor within the system under examination.

The row above the top row of the square matrix, i.e. Row 1 , is reserved for components of the system map. In its original form, the system mapping framework includes six components (namely, TIS Life Cycle, Policy Mix, Context, Institutions, Infrastructure and Facilitating Services) of a system's environment as indicated earlier in Section 3.2.

MATISE allows users to insert as many group components as they deem necessary to best describe their system.

We identify three different types of relationships for the innovation system maps for climate change: positive, negative and neutral or undefined. Positive relationships indicate a positive net impact of the row concept on the column concept and are represented by numbers in the scale $\{1,2,3,4,5\}$, corresponding to the qualitative scale of significance \{very low, low, medium, high, extremely high\}; these numbers, along with every other system information, can derive from stakeholder engagement and are represented by arrows of different thickness on the map. Thus, the larger the absolute value of the number is defined, the thicker the arrow in the visual representation will be. For instance and depending on the research question, a positive relationship in the nuclear power system map could indicate that an interaction between two concepts (e.g. actors or policies) would positively contribute (or is an enabler) to developing the nuclear power sector.

Respectively, negative relationships are shown by numbers in the scale $\{-1,-2,-3,-4$, $-5\}$ (corresponding to the same qualitative scale that positive numbers do); likewise, a negative interaction in the nuclear power system map could indicate that an interaction is negative (i.e. is a barrier) to developing the nuclear power system. Finally, zero values indicate neutral or undefined relationships between involved concepts (e.g. can be both positive and negative, but stakeholders remain indecisive on the sign). 


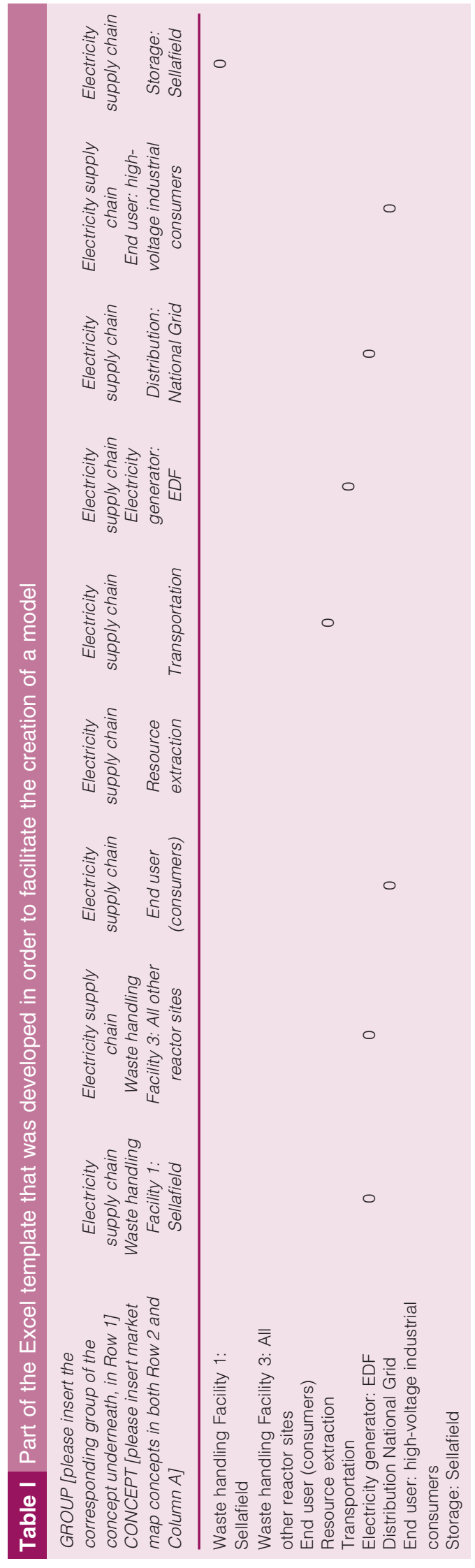

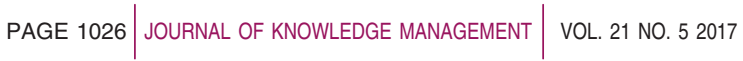


In terms of visual representation, positive relationships are represented by a green, solid arrow of variable thickness; negative ones are represented by a red, dashed arrow of variable thickness; and neutral or undefined ones are represented by a black, dotted arrow of fixed three-pixel thickness.

Optionally, one can use the Label Matrix, in the second tab of the input Excel file, and assign short text (labels) to describe those interactions. The text will only appear if a specific label is placed to describe an existing interaction. This facility is a potentially important feature of MATISE, not only in terms of visualisation but also with regard to building an audit trail of the discussions. For example, in a group discussion, stakeholders can disagree about values; some may consider a low-emission solution as bad for labour employment in conventional fossil fuel-based sectors, whereas others may believe that the solution will create new employment in research, deployment and diffusion of clean technologies. As a group, stakeholders may balance their opinions by agreeing on, e.g. a slightly positive employment generation impact, but MATISE can store both opinions, which, for example, policymakers can consult when they consider the result of the system map.

An example of how the information provided in the Adjacency (relationship) and Label (description) matrices is visualised, when using MATISE, into a system map can be seen in Figure 3.

Finally, the third tab of the Excel template file is a "how-to" guide with a set of specific instructions on how to use and fill in the file.

After the .xIs/.xlsx model has been created, MATISE can be used to supervise, edit and convert the model into a graphical modelling language model, as can be viewed in Figure 2. Specifically, the tool enables:

- creating a model from scratch from within the tool;

- importing an Excel (.xls or .xlsx) model;

- adding, deleting or modifying components/groups easily;

- adding, deleting or modifying concepts and reassigning them to different components;

- indicating whether a component is a stakeholder of the system or not;

- adding, deleting or modifying the level of significance, sign and description of the relationships between concepts;

- providing a visual overview of the system map from within the tool;

- exporting the model to an Excel (.xls or .xIsx) file, in case modifications of the model take place or a model is created from within the tool; and

- and exporting the model to a .gml file, which can then be viewed or edited in GML-supporting applications, like the free Java-based graph editor yEd.

Additionally, the program allows for the reverse process to take place, as it features importing a .gml model and enabling the user to modify it within the tool to re-export it either to a new .gml file or an .xIs/.xlsx file. This is a very useful feature, as the modeller may opt for building a simple, preliminary version of their model in the yEd graph editor, and then, as the system map becomes all the more complex and harder to supervise or update, converting the model into an Excel file and work from there in a structured way. Additionally, it ensures a smooth stakeholder engagement process, as the facilitator can provide printed copies of the map and invite experts to draw/write changes on the visual representation of a system map, which is easier for the stakeholders to understand compared to an Excel table. The facilitator can then collect the printed maps and incorporate these changes into the model in a structured way. Ultimately, this freedom to start and end in either the Excel or the visual representation means that a user can easily work on the interface they are 
more familiar with at the initial stages of building a system map, and as map complexity increases, working in Excel can make it easier for the modeller to update and supervise the model.

The GUI of MATISE is displayed in Figure 4 with information based on the UK nuclear power system map[3]. By pressing the " \pm " button in the "Concepts" area, the "Insert or Delete Concepts" wizard allows the user to add, edit or remove concepts, reassign them to different components and determine if these represent system actors. By pressing the " \pm " button in the "Components/Groups" area, the user may add new or delete existing groups. By selecting a specific concept from the list, the corresponding component to which the concept is assigned is highlighted, whereas selecting a specific component from the list will only show the concepts assigned to this component. Instructions on how to use the adjacency (links) and labels matrices can be accessed via the "?" button. The "File" menu includes the options of importing and exporting a .mat or .xIs/.xlsx model, as well as importing a .gml model.

Finally, the "View System Map" button opens a visual overview of the system map within the program for quick supervision reasons, whereas the "Export GML File" button exports the model into a .gml file to be viewed and further edited by a GML-supporting application,

\section{Figure 4 A snapshot of the GUI of MATISE}

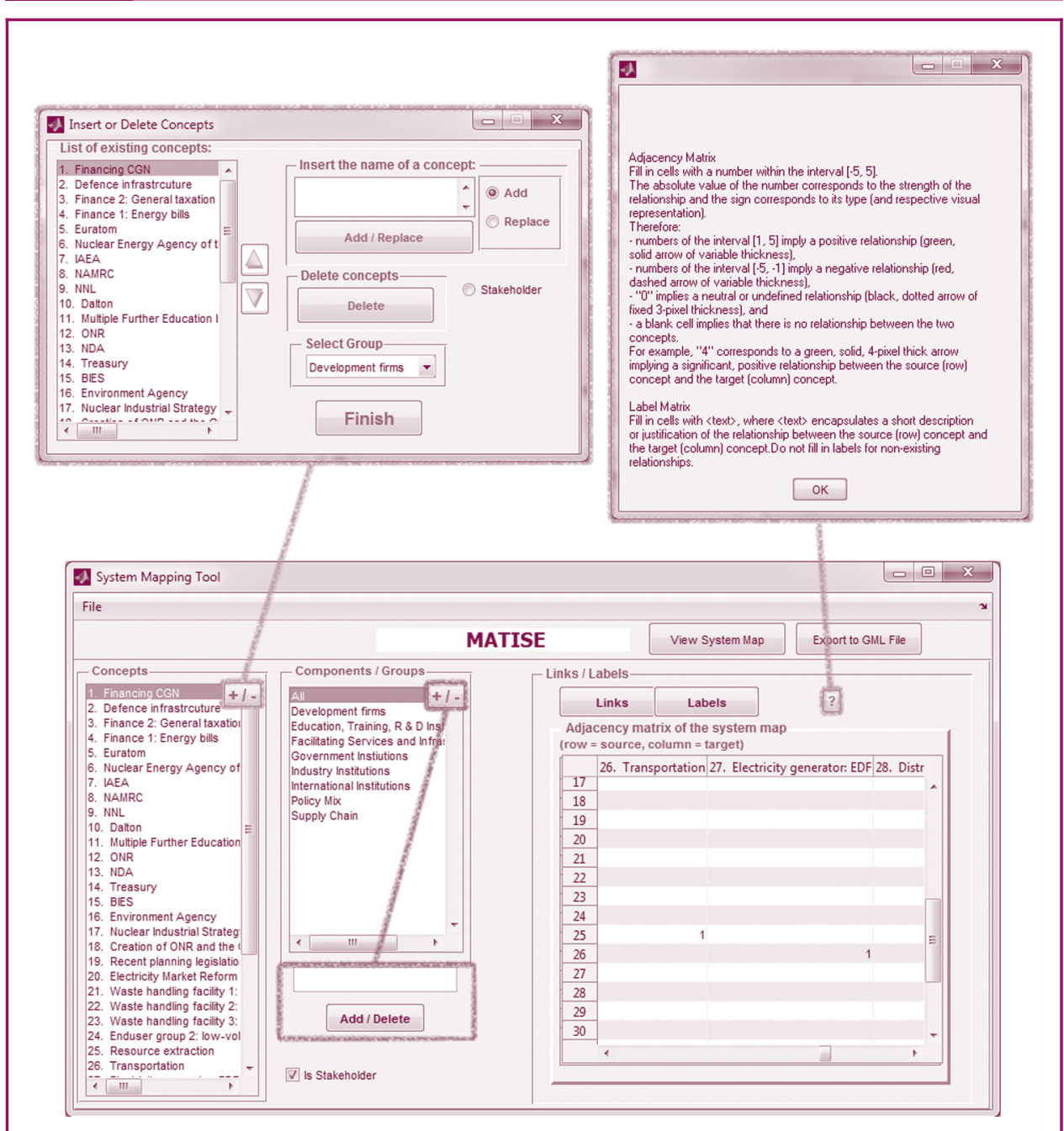


such as the yEd graph editor. After selecting an optimal layout in $\mathrm{yEd}$, the UK nuclear power system map, as exported from the tool, can be viewed in Figure 5.

Given the defined set of visualisation options and tool guidelines, in combination with yEd's layout automation that provides a "clean" visual output, the proposed methodological framework promotes uniformity and consistency across various versions of the same system map when the user aims to produce more than one narratives for a particular system or across different system maps when drawing comparisons is among the goals of the exercise.

\subsection{Integration with other modelling approaches}

Although system mapping - as a qualitative modelling technique of significant added value, as discussed in Section 3 - can produce valuable policy recommendations with regard to climate mitigation and adaptation on its own, it can also support the challenging task of developing robust transition pathways as part of an integrated methodological process. To this end, system mapping can inform quantitative modelling methodologies of key dynamics, system boundaries and contextual factors, as well as of critical policy instruments within the current or an envisioned policy mix that are perceived to be potentially appropriate or successful. In another approach or at a different stage of an integrated methodological framework, system maps can also provide the basis for fuzzy cognitive mapping (FCM), as discussed in Nikas and Doukas (2016). FCM is another modelling technique which has the same basic principles as system maps in that it aims to capture and map system dynamics based on the perceptions of multiple stakeholders that are elicited through semi-structured qualitative interviews (Samarasinghe and Strickert, 2013). Its core difference from system mapping is that it exclusively captures

\section{Figure 5 The UK Nuclear Power system map, as compiled through secondary} research and a Nuclear Power stakeholder engagement workshop

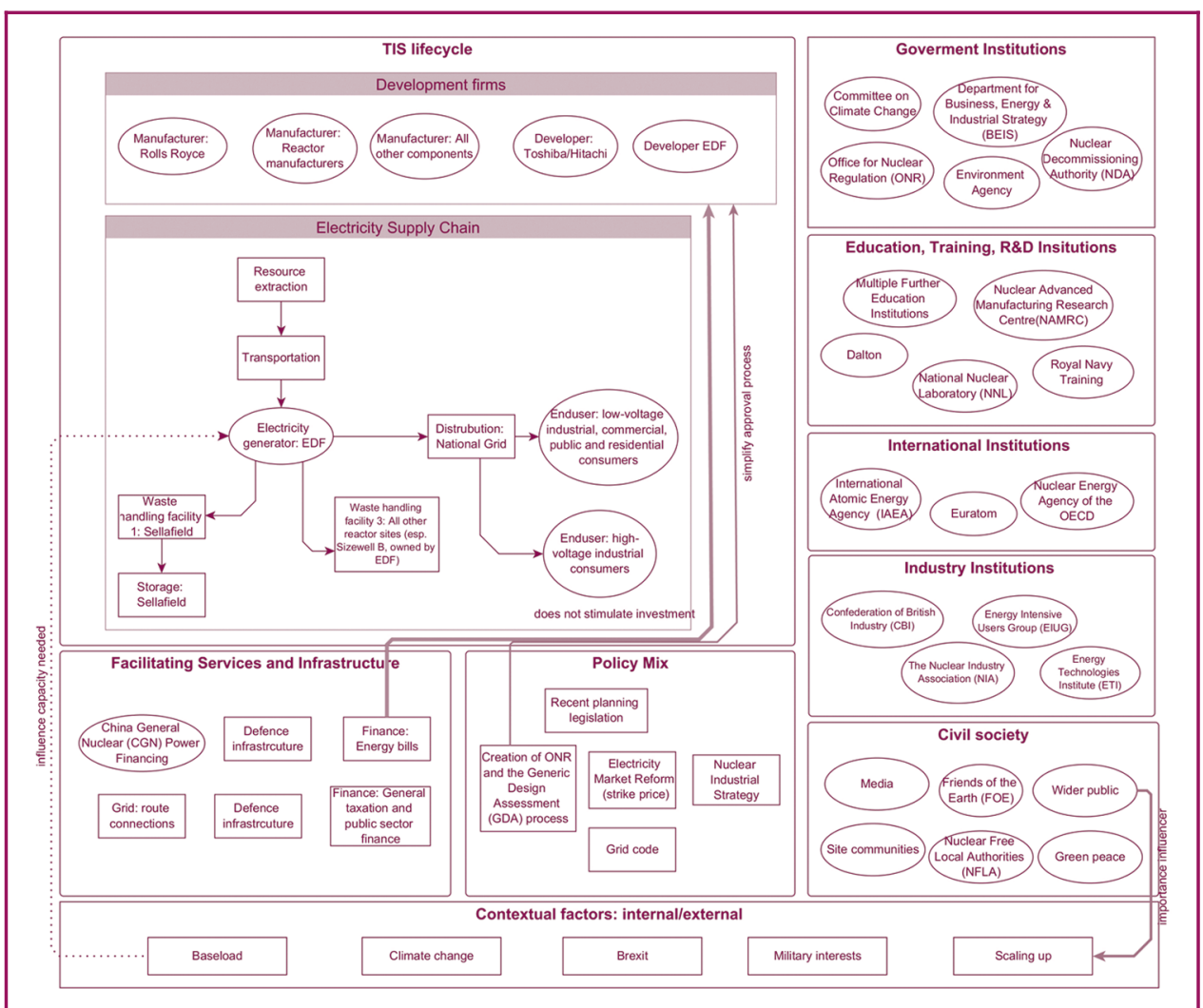

VOL. 21 NO. 52017 JOURNAL OF KNOWLEDGE MANAGEMENT $\mid$ PAGE 1029 
cause-and-effect relationships within a system which furthermore are quantified, thus allowing for simulations during which the activation level of every system concept is computed based on its initial value as well as the propagated weight values of concepts that have an impact on it (Mourhir et al., 2016). By narrowing in on specific interactions within a system map so that it only includes causal relations and then enhancing or causing contention within the system through stakeholder engagement, system mapping can not only provide the basis of FCM but also include system dynamics that have been obtained in a structured and organised way and might have otherwise eluded stakeholders' thinking and input when asked during semi-structured qualitative interviews that simply revolve around quantifying concepts and links. Finally, because FCM is also based on the development of an adjacency (or weight) matrix which too comprises system components and single or bi-directional causal relationships (Htun et al., 2016), MATISE can prove valuable in the process of directly transforming a system map into a fuzzy cognitive map by extracting the GML model into an XLS matrix; alternatively, MATISE can also support FCM by allowing for easy transformation of a visually designed FCM into an adjacency matrix, so that the latter can be used for driving simulations.

\section{Conclusions}

The proposed methodological framework for evaluating complex innovation systems for climate change is based on the system mapping approach and can be built on valuable stakeholder knowledge and expertise. It begins by defining conceptual boundaries of a system by identifying all relevant actors, policies and functions within key components of an innovation system, namely, the life cycle of the complete supply chain; the environment of enablers and barriers that directly or indirectly impact the system; and facilitating services that are external to the system but are fundamentally necessary. It later involves capturing and delving into the past and present dynamic interactions between these actors, policies and functions. Building on the identified system dynamics, the framework finally allows for evaluating pathways towards low-carbon, climate-resilient economies by exploring such dynamics while also assessing different policy strategies.

In this direction, a dedicated software application has been designed, which introduces a structured format of system representation, thus allowing for easy creation, modification and supervision of large, often cross-sectoral and complex systems. To this end, MATISE not only provides a practical approach to system mapping in an organised and structured fashion but also acts as a bridge between two very different formats of a system map, that is an adjacency matrix and its visual representation, allowing the user to work on either format at any stage of the process and depending on their preferences.

The proposed system maps framing and dedicated tool can, moreover, assist with comparison analysis of different innovation systems (e.g. of a particular sector across a large number of countries or of different sectors within the same country) because they feature consistent representation of elements and building blocks across varied system maps.

System maps constitute not only a helpful analytical and visual support tool but also a means of codifying tacit knowledge that is embedded in stakeholders. This knowledge is captured and documented in a tool which helps to record the research process and to improve the transparency of research outcomes. For instance, the analysis of current pathways and the development of potential new low carbon pathways can be based on an understanding of the system dynamics identified by stakeholders rather than an individual researcher who theoretically creates a model based on specific assumptions of a given system. Additionally, due to the participatory nature of the tool, the system map can help to identify problematic areas or elements that are working well within an innovation system based on interactions that are not completely obvious to a single stakeholder group but emerge as a result of a consolidated stakeholder engagement process. This overarching 
system perspective may also be valuable when addressing complex problems related to climate change that impact a significant group of stakeholders. The bottom up approach provides a platform for stakeholders who may not be typically approached, such as margined stakeholder groups, to participate in developing climate change pathways. The tool, therefore, is a good starting point to systematically include an obvious but frequently overlooked aspect of tackling climate change: the dynamics of the human dimension.

\section{Notes}

1. MATISE is free and open source software, available under a permissive BSD license from http:// transrisk-project.eu/matise.zip

2. http://docs.yworks.com/yfiles/doc/developers-guide/gml.html

3. The UK nuclear power system map is based on a case study carried out in TRANSrisk, a Horizon 2020 project carried out from 2015 to 2018. The system map was developed based on desk research and received inputs from a stakeholder nuclear power stakeholder workshop carried out in London on 21 October 2016.

\section{References}

Albu, M. (2010), Emergency Market Mapping and Analysis Toolkit, Oxfam GB.

Albu, M. and Griffith, A. (2005), "Mapping the market: a framework for rural enterprise development policy and practice", Practical Action (formerly ITDG, Rugby.

Albu, M. and Griffith, A. (2006), "Mapping the market: participatory market-chain development in practice", Small Enterprise Development, Vol. 17 No. 2, pp. 12-22.

Alvarez Tinoco, G.D.R. (2011), "Evolution of capabilities in agribusiness: the case of the Mexican dairy sector", Doctoral Dissertation, University of Sussex.

Apraise (2014), "Understanding Policy Contexts and Stakeholder Behaviour for Consistent and Coherent Environmental Policies - A synthesis of results from the APRAISE project", available at: http://apraise.org/sites/default/files/apraise_synthesis_document_2.pdf

Asheim, B. and Gertler, M.S. (2005), "The geography of innovation: regional innovation systems", in Fagerberg, J., Mowery, D.C. and Nelson, R.R. (Eds), The Oxford Handbook of Innovation, Oxford University Press, pp. 291-317.

Asheim, B.T. and Isaksen, A. (1997), "Location, agglomeration and innovation: towards regional innovation systems in Norway?", European Planning Studies, Vol. 5 No. 3, pp. 299-330.

Axelrod, R. (Ed.). ( 1976), Structure of Decision: The Cognitive Mapping Approach to Decision Making, Princeton University Press, pp. 221-250.

Bergek, A., Hekkert, M. and Jacobsson, S. (2008), "Functions in innovation systems: a framework for analysing energy system dynamics and identifying goals for system-building activities by entrepreneurs and policy makers", in Foxon, T., Köhler, J. and Oughton, C. (Eds), Innovations for a Low Carbon Economy: Economic, Institutional and Management Approaches, Edward Elgar, Cheltenham, pp. 79-111.

Bergek, A., Hekkert, M., Jacobsson, S., Markard, J., Sandén, B. and Truffer, B. (2015), "Technological innovation systems in contexts: conceptualizing contextual structures and interaction dynamics", Environmental Innovation and Societal Transitions, Vol. 16, pp. 51-64.

Bioteam (2016), "Market system map reports", available at: www.sustainable-biomass.eu/index.php/ publications

Boots, M.G., Schaeffer, G.J., de Zoeten, C., Mitchell, C., Anderson, T., Morthorst, P.E., Nielsen, I., Kühn, I., Bräuer, W., Stronzik, M. and Gual, M. (2001), "The interaction of tradable instruments in renewable energy and climate change markets", Final report, Energy Research Centre of the Netherlands (ECN).

Boulding, K.E. (1956), "General systems theory-the skeleton of science”, Management Science, Vol. 2 No. 3, pp. 197-208. 
Breschi, S. and Malerba, F. (1997), Sectoral Innovation Systems: Technological Regimes, Schumpeterian Dynamics, and Spatial Boundaries: Systems of Innovation: Technologies, Institutions and Organizations, Centro Studi sui Processi di Internazionalizzazione, pp. 130-156.

Bürli, M., Aw-Hassan, A. and Rachidi, Y.L. (2008), "The importance of institutions in mountainous regions for accessing markets: an example from the Moroccan High Atlas”, Mountain Research and Development, Vol. 28 No. 3, pp. 233-239

Byrne, K.G., March, J., McGuire, S., Meissner, L. and Sperling, L. (2013), "The role of evidence in humanitarian assessment: the seed system security assessment and the emergency market mapping and analysis", Disasters, Vol. 37 No. 1, pp. S83-S104.

Carlsson, B. and Jacobsson, S. (1997a), "Diversity creation and technological systems: a technology policy perspective", in Edquist, C. (Ed.), Systems of Innovation: Technologies, Institutions and Organizations, Pinter Publishers, London, p. 7.

Carlsson, B. and Jacobsson, S. (1997b), "In search of a useful technology policy-general lessons and key issues for policy makers", Technological systems and Industrial Dynamics, Kluwer Press, Boston, MA, pp. 299-315.

Carlsson, B. and Stankiewicz, R. (1991), "On the nature, function and composition of technological systems", Journal of Evolutionary Economics, Vol. 1 No. 2, pp. 93-118.

Carlsson, B., Jacobsson, S., Holmén, M. and Rickne, A. (2002), "Innovation systems: analytical and methodological issues", Research Policy, Vol. 31 No. 2, pp. 233-245.

Chaminade, C. and Edquist, C. (2006), "From theory to practice: the use of the systems of innovation approach in innovation policy", in Hage, J. and Meeus, M. (Eds), Innovation, Science and Institutional Change, Oxford University Press, pp. 141-158.

Cooke, P. (1992), "Regional innovation systems: competitive regulation in the new Europe", Geoforum, Vol. 23 No. 3, pp. 365-382.

Cooke, P. (2001), "Regional innovation systems, clusters, and the knowledge economy", Industrial and Corporate Change, Vol. 10 No. 4, pp. 945-974.

Cooke, P. (2002), "Regional innovation systems: general findings and some new evidence from biotechnology clusters", The Journal of Technology Transfer, Vol. 27 No. 1, pp. 133-145.

Cooke, P. (2004), "Introduction: regional innovation systems - an evolutionary approach", in Cooke, P., Heidenreich, M. and Braczyk, H.J. (Eds), Regional Innovation Systems: The Role of Governances in a Globalized World, Routledge.

Dougherty, B. and Fencl, A. (2009), Handbook for Conducting Technology Needs Assessment for Climate Change, United Nations Development Programme, New York, NY.

Edquist, C. (2005), "Systems of innovation: perspectives and challenges", in Fagerberg, J., Mowery, D.C. and Nelson, R.R. (Eds), The Oxford Handbook of Innovation, 1st ed., Oxford University Press, Oxford.

Fink, M. (2014), "Constraints and opportunities for horticultural smallholders in the Nacala Corridor in Northern Mozambique".

Flamos, A. and Begg, K. (2010), "Technology transfer insights for new climate regime", Environment, Development and Sustainability, Vol. 12 No. 1, pp. 19-33.

Freeman, C. (1987), Technology Policy and Economic Performance: Lessons from Japan, Pinter, London.

Freeman, C. (1995), "The 'national system of innovation'in historical perspective", Cambridge Journal of Economics, Vol. 19 No. 1, pp. 5-24.

Freeman, C. (2002), "Continental, national and sub-national innovation systems - complementarity and economic growth", Research Policy, Vol. 31 No. 2, pp. 191-211.

Geels, F.W. (2004), "From sectoral systems of innovation to socio-technical systems: insights about dynamics and change from sociology and institutional theory", Research Policy, Vol. 33 No. 6, pp. 897-920.

Giuliani, A., Karagöz, A. and Zencirci, N. (2009), "Emmer (Triticum dicoccon) production and market potential in marginal mountainous areas of Turkey", Mountain Research and Development, Vol. 29 No. 3, pp. 220-229. 
Gray, S.A., Gray, S., Cox, L.J. and Henly-Shepard, S. (2013), "Mental modeler: a fuzzy-logic cognitive mapping modeling tool for adaptive environmental management", 46th Hawaii International Conference on System Sciences (HICSS), Wailea, Maui, HI, 7-10 January, IEEE, pp. 965-973.

Hekkert, M.P., Suurs, R.A., Negro, S.O., Kuhlmann, S. and Smits, R.E. (2007), "Functions of innovation systems: a new approach for analysing technological change", Technological Forecasting and Social Change, Vol. 74 No. 4, pp. 413-432.

Hobday, M. (1998), "Product complexity, innovation and industrial organisation", Research Policy, Vol. 26 No. 6, pp. 689-710.

Hobday, M., Rush, H. and Tidd, J. (2000), "Innovation in complex products and system", Research Policy, Vol. 29 No. 7, pp. 793-804.

Htun, H., Gray, S.A., Lepczyk, C.A., Titmus, A. and Adams, K. (2016), "Combining watershed models and knowledge-based models to predict local-scale impacts of climate change on endangered wildlife", Environmental Modelling \& Software, Vol. 84, pp. 440-457.

Karakosta, C., Flamos, A., Doukas, H. and Vaturi, A. (2010), "Sustainable energy technology transfers through the CDM? Application of participatory approaches for decision making facilitation", International Journal of Environmental Policy and Decision Making, Vol. 1 No. 1, pp. 1-16.

Kim, S., Suh, E. and Hwang, H. (2003), "Building the knowledge map: an industrial case study", Journal of Knowledge Management, Vol. 7 No. 2, pp. 34-45.

Kwong, E. and Lee, W.B. (2009), "Knowledge elicitation in reliability management in the airline industry", Journal of Knowledge Management, Vol. 13 No. 2, pp. 35-48.

Lagabrielle, E., Botta, A., Daré, W., David, D., Aubert, S. and Fabricius, C. (2010), "Modelling with stakeholders to integrate biodiversity into land-use planning-Lessons learned in Réunion Island (Western Indian Ocean)", Environmental Modeling \& Software, Vol. 25 No. 11, pp. 1413-1427.

Lundvall, B.A. (1992), National Innovation System: Towards a Theory of Innovation and Interactive Learning, Pinter, London.

Lundvall, B.̊.., Joseph, K.J., Chaminade, C. and Vang, J. (Eds) (2009), Handbook of Innovation Systems and Developing Countries: Building Domestic Capabilities in a Global Setting, Edward Elgar Publishing.

Malerba, F. (2002), "Sectoral systems of innovation and production", Research Policy, Vol. 31 No. 2, pp. 247-264.

Malerba, F. (2005), "Sectoral systems: how and why innovation differs across sectors", in Fagerberg, J., Mowery, D. and Nelson, R.R. (Eds), The Oxford Handbook of Innovation, Oxford University Press, Oxford.

Mourhir, A., Rachidi, T., Papageorgiou, E.I., Karim, M. and Alaoui, F.S. (2016), "A cognitive map framework to support integrated environmental assessment", Environmental Modelling \& Software, Vol. 77, pp. 81-94.

Nelson, R.R. (1993), National Innovation Systems: A Comparative Study, Oxford University Press.

Nikas, A. and Doukas, H. (2016), "Developing robust climate policies: a fuzzy cognitive map approach", Robustness Analysis in Decision Aiding, Optimization, and Analytics, Springer International Publishing, pp. 239-263.

Niosi, J. (2002), "National systems of innovations are 'x-efficient'(and x-effective): why some are slow learners", Research Policy, Vol. 31 No. 2, pp. 291-302.

Niosi, J. (2011), "Building innovation systems: an introduction to the special section", Industrial and Corporate Change, Vol. 20 No. 6, pp. 1637-1643.

Oikonomou, V., Flamos, A. and Grafakos, S. (2010), "Is blending of energy and climate policy instruments always desirable?", Energy Policy, Vol. 38 No. 8, pp. 4186-4195.

Oikonomou, V., Flamos, A. and Grafakos, S. (2014), "Combination of energy policy instruments: creation of added value or overlapping?", Energy Sources, Part B: Economics, Planning, and Policy, Vol. 9 No. 1, pp. 46-56.

Padilla-Pérez, R. and Gaudin, Y. (2014), "Science, technology and innovation policies in small and developing economies: the case of Central America", Research Policy, Vol. 43 No. 4, pp. 749-759. 
Padilla-Pérez, R., Vang, J. and Chaminade, C. (2011), "Regional innovation systems in developing countries", Handbook of Innovation Systems and Developing Countriesm, Edward Elgar Publishing.

Practical Action Consulting (2009), "Small-scale bioenergy initiatives: brief description and preliminary lessons on livelihood impacts from case studies in Asia", Final re-port, prepared for PISCES and FAO by Practical Action Consulting, Latin America and Africa.

Samarasinghe, S. and Strickert, G. (2013), "Mixed-method integration and advances in fuzzy cognitive maps for computational policy simulations for natural hazard mitigation", Environmental Modelling \& Software, Vol. 39, pp. 188-200.

Soumonni, O. (2013), "Towards a technology policy for renewable energy development in Africa: a systems of innovation perspective", African Journal of Science, Technology, Innovation and Development, Vol. 5 No. 4, pp. 289-295.

Sperling, L. (2008), When Disaster Strikes: A Guide to Assessing Seed System Security No. 363, CIAT.

TEC (2014), "Good practices of technology needs assessments", Ninth Meeting of the Technology Executive Committee, Background Paper, Langer Eugen, Bonn, 18-21 August, available at: http:// unfccc.int/ttclear/misc_StaticFiles/gnwoerk_static/TEM_TEC_meetings/d8024d9b950f43d594fc17fd2 2b5477a/6d4c53c874c74baab1ee4b287ec9292e.pdf

Transrisk (2016), "Transitions pathways and risk analysis for climate change mitigation and adaption strategies”, EU Horizon 2020 Programme, available at: http://transrisk-project.eu/

Trochim, W.M. (1989), "An introduction to concept mapping for planning and evaluation", Evaluation and Program Planning, Vol. 12 No. 1, pp. 1-16.

UNFCCC (2013), Third Synthesis Report on Technology Needs Identified by Parties Not Included in Annex I to the Convention, FCCC/SBSTA/2013/INF.7, available at: http://unfccc.int/resource/docs/ 2013/sbsta/eng/inf07.pdf

van der Gaast, W., Begg, K. and Flamos, A. (2009), "Promoting sustainable energy technology transfers to developing countries through the CDM", Applied Energy, Vol. 86 No. 2, pp. 230-236.

Voinov, A. and Bousquet, F. (2010), "Modelling with stakeholders", Environmental Modelling \& Software, Vol. 25 No. 11, pp. 1268-1281.

Von Bertalanffy, L. (1950), "An outline of general system theory", British Journal for the Philosophy of Science, No. 2, pp. 134-165.

Wells, J. (2012), Complexity and Sustainability, Vol. 26, Routledge.

\section{Author Affiliations}

Alexandros Nikas is Electrical and Computer Engineer at the School of Electrical and Computer Engineering, National Technical University of Athens, Athens, Greece.

Haris Doukas is based at the School of Electrical and Computer Engineering, National Technical University of Athens, Athens, Greece.

Jenny Lieu and Rocío Alvarez Tinoco are both based at the Science Policy Research Unit, University of Sussex, Brighton, UK.

Vasileios Charisopoulos is Electrical and Computer Engineer at the School of Electrical and Computer Engineering, National Technical University of Athens, Athens, Greece.

Wytze van der Gaast is based at the JIN Climate and Sustainability, Groningen The Netherlands.

\section{Corresponding author}

Alexandros Nikas can be contacted at: anikas@epu.ntua.gr

For instructions on how to order reprints of this article, please visit our website: www.emeraldgrouppublishing.com/licensing/reprints.htm

Or contact us for further details: permissions@emeraldinsight.com 